Association for Information Systems

AIS Electronic Library (AISeL)

Wirtschaftsinformatik 2021 Proceedings

Track 18: Future of Digital Markets and

Platforms

\title{
The Role of Complementors in Platform Ecosystems
}

Marius Deilen

Technische Universität Dortmund

Manuel Wiesche

Technische Universität Dortmund

Follow this and additional works at: https://aisel.aisnet.org/wi2021

Deilen, Marius and Wiesche, Manuel, "The Role of Complementors in Platform Ecosystems" (2021). Wirtschaftsinformatik 2021 Proceedings. 5.

https://aisel.aisnet.org/wi2021/GFuture18/Track18/5

This material is brought to you by the Wirtschaftsinformatik at AIS Electronic Library (AISeL). It has been accepted for inclusion in Wirtschaftsinformatik 2021 Proceedings by an authorized administrator of AIS Electronic Library (AISeL). For more information, please contact elibrary@aisnet.org. 


\title{
The Role of Complementors in Platform Ecosystems
}

\author{
Marius Deilen ${ }^{1}$ and Manuel Wiesche ${ }^{1}$ \\ 1 Technical University of Dortmund, Chair of Digital Transformation, Dortmund, Germany \\ \{marius.deilen, manuel.wiesche\}@tu-dortmund.de
}

\begin{abstract}
Platform ecosystems have recently drawn considerable research attention to scholars in various disciplines, as the influence of platforms is increasingly relevant in the economy. However, most research focused on the technological- and business aspect of platforms taking the viewpoint of the platform owner. Little research has been conducted to understand and analyze heterogeneous types of complementors in platform ecosystem. To this end, we conduct a literature review of relevant journals and conferences on the view of complementors in platform ecosystems. Based on this analysis we derive two important topics for future research: the heterogeneity of complementors in platform ecosystems and the individual evaluation of complementors. This scientific article contributes to the understanding of complementors in platform ecosystems in the information systems literature by structuring the relevant research of the complementors with respect to their role and contributions to platform ecosystem and presenting possible avenues for future research.
\end{abstract}

Keywords: platform, ecosystem, complementor, innovation, literature review

\section{Introduction}

Digital markets and digital platform ecosystems are becoming increasingly important in the economy. As of 2019, seven of the ten most valuable publicly listed companies measured by market capitalization, including Apple, Amazon, Alphabet, Facebook, Alibaba, Tencent and Microsoft rely on platform business models [1]. These companies managed to create a sustainable platform ecosystem in which the innovations are not generated by the platform provider itself, but by complementors ${ }^{1}$ in the platform ecosystem [3-6]. The actors in a platform ecosystem involve typically a central actor (platform owner or hub firm) that

1 In scientific literature, scholars use various synonyms for developers on platforms (see Table 1). In the following course of this paper, we use the expression "complementor" according to the definition of Brandenburger and Nalebuff [2] as an acronym for "the developer of a complementary product". 
orchestrates value creation and value appropriation by engaging complementors, to operate in the platform ecosystem [7-9]. These complementors provide complementary goods to the ecosystem defined as any other product or service, which enhances the attractiveness of the focal product or service such as add-ons, extensions or modules $[2,10,11]$. Hence, the success of a platform increasingly depends on active complementors who develop innovative complementary goods to stimulate user demand for the platform [12].

With low barriers to entry, little or no up-front costs for developing and publishing complementary goods and simultaneous direct market access to a large number of potential customers, platform ecosystems provide an interesting business environment for various complementors [3, 13, 14]. However, the lens through which the literature has focused on research with regard to complementors in platform ecosystems has been predominantly economic or technical in nature taking the viewpoint of platform providers $[7,15]$. Although there is an academic consensus in research that complementors make a substantial contribution for enriching $[7,12,16]$ and expanding platform ecosystems $[8,17,18]$, much less attention has been devoted to investigate the organizational, social and economic aspects of the complementor community.

Towards this end, we conducted a literature review, focusing on the role of complementors in platform ecosystems. In a first step, we try to conceptualize the complementors in platform ecosystem, since existing literature often uses synonyms like "developer" [8, 19, 20], "partner" [21, 22] and "complementor" [7, $12,20,23,24]$ homogenously without distinguishing socio- and demographic dimensions of a complementor. In a second step, we investigate how the existing literature investigates and classifies the contributions of complementors to platform ecosystems. In the last step, we investigate the relationship between platform owner and complementor on four different key dimensions. By showing the state-of-the-art literature, our review reveals open topics for scholars in IS and management with regard to the role of complementors in platform ecosystems. Addressing these open issues will significantly contribute to the understanding of heterogeneous complementor structures in platform ecosystems. The results are useful for both theory and practice, as we show that the role of the complementors and their heterogeneous structure has so far been largely overlooked in research, calling for further research in this area.

In the following, section 2 starts with a description of the literature review process on complementors in platform ecosystems. Afterwards, we present the results by structuring the contributions according to different perspectives on the role of complementors in platform ecosystems. The paper concludes with a discussion of findings and limitations.

\section{Design of the Literature Review}

In this literature review, we looked for publications that (a) focus on the platform ecosystem as unit of analysis and (b) emphasis on the role of complementor in 
platform ecosystems. We examined relevant outlets following the guidelines of Webster and Watson [25] and vom Brocke et al. [26].

Table 1: Summary of synonyms for platform and complementors

\begin{tabular}{|c|c|c|}
\hline $\begin{array}{c}\text { Category A } \\
\text { platform ecosystem }\end{array}$ & \multirow{3}{*}{ 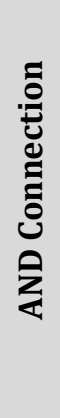 } & $\begin{array}{c}\text { Category B } \\
\text { complementors }\end{array}$ \\
\hline $\begin{array}{l}\text { platform } \\
\text { ecosystem } \\
\text { platform ecosystem } \\
\text { digital platform } \\
\text { digital platform ecosystem } \\
\text { platform-based ecosystem }\end{array}$ & & $\begin{array}{l}\text { partner* } \\
\text { complementor* } \\
\text { developer* } \\
\text { entrepreneur* } \\
\text { start-up* } \\
\text { entrepreneurship } \\
\text { digital entrepreneurship }\end{array}$ \\
\hline OR Connection & & OR Connection \\
\hline
\end{tabular}

In the first step, since both platforms and complementors are associated with different terms in scientific literature, we compiled synonyms for both parameters "platform ecosystem" and "complementor" in order to ensure the highest possible coverage of all scientific writings as Table 1 shows. The internal linking of the terms via the OR operator for each search string and the subsequent linking via the AND operator ensured that all articles dealing with the complementor perspective in platform ecosystems are included.

In the second step, we conducted a literature search based on the mentioned keywords in all journals included in the Senior Scholars' Basket of Journals of the Association for Information System and in the Financial Times 50. ${ }^{2}$ Additionally, we focused on contributions published at the following conference to encompass the most current research topics in the field of platform economics: International Conference on Information Systems (ICIS), European Conference on Information Systems (ECIS), Americas' Conference on Information Systems (AMCIS), Hawaii International Conference on System Sciences (HICSS), and Wirtschaftsinformatik (WI). For all articles provided in the search results, the final selection process included an examination of the abstract of each article based on our search criteria (a) focus on the platform ecosystem as unit of analysis and (b) emphasis on the role of complementor in platform ecosystems. If the match with our search criteria was unclear after analyzing the abstract, the full text was read for the decision on inclusion in the final dataset.

Third, in line with the guideline of vom Brocke et al. [26] and based on the publications collected so far, we carried out a forward and backward search, resulting in additional five articles from a variety of sources. Among the additional sample, we found published textbooks and articles from several economic journals relating to the field of Information Systems and Management.

2 The VHB-JOURQUAL3 list for IS and the Financial Times' FT-50 list are available online at https://vhbonline.org/fileadmin/user_upload/JQ3_WI.pdf and https://www.ft.com/content/3405a512-5cbb-11e1-8f1f-00144feabdc0 
Based on our search process and the forward and backward search, we were able to find a total of 224 relevant articles. After analysis of these articles based on the unit of analysis (a) focus on the platform ecosystem and (b) emphasis on the role of complementor in platform ecosystems, we obtained a final literature data set of 60 relevant articles. Table 2 shows a summary of the literature search process and the selected relevant article per outlet category.

Table 2: Summary of the literature search process

\begin{tabular}{|l|l|r|r|}
\hline Outlet & Hits & Selected \\
\hline IS Journals & All Journals within the AIS Basket of Eight & 49 & 12 \\
\hline $\begin{array}{l}\text { Management } \\
\text { Journals }\end{array}$ & All journals within the Financial Times 50 & 135 & 32 \\
\hline IS Conferences & ICIS, ECIS, AMCIS, HICSS, WI & 40 & 11 \\
\hline Other & Other Journals, Conferences and Books & - & 5 \\
\hline Total & $\mathbf{2 2 4}$ & $\mathbf{6 0}$ \\
\hline
\end{tabular}

\section{Empirical Results on Complementors in Platform Ecosystems}

In this section, we summarize the findings and coded articles of the literature analysis on complementors in platform ecosystems based on the concept matrix illustrated in Table 3. Based on our analysis, we structure the concept matrix along three dimensions: 1) the conceptualization of complementors, 2) the contributions of complementors to platform ecosystems, and 3) the relationship between complementor and platform owner.

Table 3: Concept matrix - role of complementors in platform ecosystems

\begin{tabular}{|c|c|c|c|c|c|c|c|c|c|c|}
\hline \multirow[t]{2}{*}{ Article } & \multicolumn{3}{|c|}{$\begin{array}{l}\text { Conceptualization } \\
\text { of complementors }\end{array}$} & \multicolumn{3}{|c|}{$\begin{array}{l}\text { Contribution of } \\
\text { complementors }\end{array}$} & \multicolumn{4}{|c|}{$\begin{array}{c}\text { Relationship platform } \\
\text { owner and complementor }\end{array}$} \\
\hline & 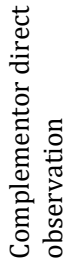 & 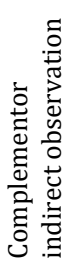 & 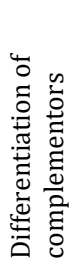 & $\begin{array}{l}0 \\
.0 \\
0 \\
0 \\
0 \\
\vdots \\
\vdots \\
0 \\
\vdots \\
0 \\
.0 \\
\vdots\end{array}$ & 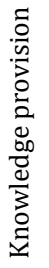 & 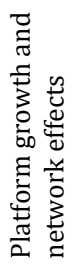 & 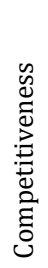 & 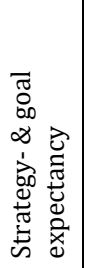 & 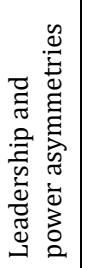 & 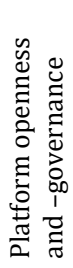 \\
\hline \multicolumn{11}{|l|}{ AIS Basket of Eight } \\
\hline $\begin{array}{l}\text { Anderson, Parker \& } \\
\text { Tan (2014) }\end{array}$ & & $\mathrm{x}$ & & $\mathrm{X}$ & & $\mathrm{x}$ & & & $\mathrm{x}$ & $\mathrm{x}$ \\
\hline $\begin{array}{l}\text { Benlian, Hilkert \& } \\
\text { Hess (2015) }\end{array}$ & & $\mathrm{x}$ & $\mathrm{x}$ & & & & & & & $\mathrm{x}$ \\
\hline $\begin{array}{l}\text { Bergvall-Kåreborn \& } \\
\text { Howcroft (2014) }\end{array}$ & & $\mathrm{x}$ & & $\mathrm{x}$ & & $\mathrm{x}$ & $\mathrm{x}$ & & & $\mathrm{x}$ \\
\hline
\end{tabular}




\begin{tabular}{|c|c|c|c|c|c|c|c|c|c|c|}
\hline $\begin{array}{l}\text { Ghazawneh \& } \\
\text { Henfridsson (2015) }\end{array}$ & & $\mathrm{x}$ & & & & & $\mathrm{x}$ & & & $\mathrm{x}$ \\
\hline $\begin{array}{l}\text { Ghazawneh \& } \\
\text { Henfridsson (2015) }\end{array}$ & $\mathrm{x}$ & & & $\mathrm{x}$ & $\mathrm{x}$ & $\mathrm{x}$ & $\mathrm{X}$ & & $\mathrm{x}$ & $\mathrm{x}$ \\
\hline $\begin{array}{l}\text { Huber, Kude \& } \\
\text { Dibbern (2017) }\end{array}$ & & $\mathrm{x}$ & & $\mathrm{x}$ & & & & & $\mathrm{x}$ & $\mathrm{x}$ \\
\hline Hurni et al. (2020) & $\mathrm{x}$ & & $\mathrm{x}$ & $\mathrm{x}$ & & $\mathrm{x}$ & & $\mathrm{x}$ & $\mathrm{x}$ & \\
\hline Oh et al. (2015) & & $\mathrm{x}$ & & $\mathrm{X}$ & & & & $\mathrm{X}$ & & $\mathrm{x}$ \\
\hline $\begin{array}{l}\text { Parker, Van Alstyne } \\
\text { \& Jiang (2017) }\end{array}$ & $\mathrm{x}$ & & & $\mathrm{x}$ & & $\mathrm{x}$ & $\mathrm{x}$ & & $\mathrm{x}$ & $\mathrm{x}$ \\
\hline $\begin{array}{l}\text { Qiu, Gopal \& Hann } \\
\text { (2017) }\end{array}$ & $\mathrm{x}$ & & $\mathrm{x}$ & $\mathrm{x}$ & $\mathrm{x}$ & & & $\mathrm{x}$ & $\mathrm{x}$ & $\mathrm{x}$ \\
\hline Sarker et al. (2020) & & $\mathrm{x}$ & & $\mathrm{x}$ & & $\mathrm{x}$ & & & $\mathrm{x}$ & $\mathrm{x}$ \\
\hline Tiwana (2015) & & $\mathrm{x}$ & & & & $\mathrm{x}$ & & & & $\mathrm{x}$ \\
\hline \multicolumn{11}{|c|}{ Financial Times 50, Conferences and other } \\
\hline 48 articles & 14 & 34 & 13 & 43 & 12 & 25 & 33 & 16 & 30 & 43 \\
\hline Total & 18 & 42 & 16 & 52 & 14 & 32 & 37 & 19 & 37 & 54 \\
\hline
\end{tabular}

\subsection{Conceptualization of Complementors in Platform Ecosystem Literature}

The initial analysis of our iterative coding process literature revealed that literature consider complementors frequently, but almost exclusively in direct relation to other aspects of a platform ecosystem. Of the 60 identified and relevant outlets, only 18 articles look at the complementor in detail, while the other 42 articles examine in particular the interrelation between the complementor and different aspects of a platform. As Table 4 illustrates, articles dealing directly or indirectly with the role of the complementor in platform ecosystems show different criteria by which scholars conceptualize complementors.

Table 4: Conceptualization of Complementors in Platform Ecosystems

\begin{tabular}{|l|l|l|}
\hline $\begin{array}{l}\text { Differentiation criteria of } \\
\text { complementor }\end{array}$ & $\begin{array}{l}\text { Conceptualization of } \\
\text { complementor type }\end{array}$ & Reference \\
\hline $\begin{array}{l}\text { (1) Complementor size } \\
\text { Criterion differentiated in } 13 \text { studies } \\
\text { Criterion not differentiated in } 47 \\
\text { studies }\end{array}$ & $\begin{array}{l}\text { Major developer } \\
\text { Minor developer } \\
\text { De novo complementors } \\
\text { Small complementor } \\
\text { Large complementor }\end{array}$ & {$[18,27-31]$} \\
\hline $\begin{array}{l}\text { (2) Scope of remuneration } \\
\text { Criterion differentiated in 2 studies } \\
\text { Criterion not differentiated in 58 } \\
\text { studies }\end{array}$ & $\begin{array}{l}\text { Full-time paid developer } \\
\text { Part-time paid developer } \\
\text { Unpaid developer }\end{array}$ & {$[31,32]$} \\
\hline $\begin{array}{l}\text { (3) Incentive of complementor } \\
\text { Criterion differentiated in 4 studies } \\
\text { Criterion not differentiated in 56 } \\
\text { studies }\end{array}$ & $\begin{array}{l}\text { Employed developers } \\
\text { Entrepreneurs, Indies } \\
\text { Hobby developers }\end{array}$ & {$[14,19,23$,} \\
\end{tabular}




\begin{tabular}{|l|l|l|}
\hline $\begin{array}{l}\text { (4) Scope of contribution to } \\
\text { platform ecosystem } \\
\text { Criterion differentiated in } 5 \text { studies } \\
\text { Criterion not differentiated in } 55 \\
\text { studies }\end{array}$ & $\begin{array}{l}\text { Small content suppliers } \\
\text { Large content suppliers } \\
\text { Developer with small user base } \\
\text { Developer with large user base }\end{array}$ & $\begin{array}{l}{[5,19,33-} \\
35]\end{array}$ \\
\hline $\begin{array}{l}\text { (5) Organizational form } \\
\text { Criterion differentiated in } 7 \text { studies } \\
\text { Criterion not differentiated in } 53 \\
\text { studies }\end{array}$ & $\begin{array}{l}\text { Individual complementor } \\
\text { perspective }\end{array}$ & $\begin{array}{l}{[4,5,27,} \\
29,31,36, \\
37]\end{array}$ \\
$\begin{array}{l}\text { Criterion differentiated in } 3 \text { studies } \\
\text { Criterion not differentiated in } 57 \\
\text { studies }\end{array}$ & Institutional complementor & {$[5,28,29]$} \\
\hline
\end{tabular}

The articles distinguish complementors in platform ecosystems especially according to their organization size. Benlian et al. [30], for example, examine how complementors perceive the openness of a platform from their perspective. In this context, Benlian et al. [30] distinguish complementors for their research objective strictly according to their organizational structure and derived the distinction between employed developers, entrepreneur, hobby developers and others. Boudreau et al. [29] use similar distinguishing features by deriving the heterogeneity between complementors in platform ecosystems based on the number of employees of the respective complementor to investigate the extent to which intellectual property rights protection mechanisms differ between small and large complementors on platforms.

Other studies distinguish between complementors in platform ecosystems in terms of their scope of remuneration. For example, Boudreau \& Jeppesen [31] differentiate complementors in terms of their compensation structure in order to investigate whether complementors react to the growth of a platform in a competitive context despite the lack of compensation. Other studies link the remuneration of complementors to the degree of employment in order to take into account the heterogeneity of complementors in platform ecosystems. For example, Schaarschmidt et al. [32] classify complementors according to the degree of employment into full-time paid developer, part-time paid developer and not paid developer to investigate the relationship between lead userness and developers' innovative work behavior.

Another distinguishing feature is the nature of the incentive for the complementor to engage and provide value on the platform. In order to create a heterogeneity in the complementor structure, Hilkert et al. [14] conceptualize complementors as salaried programmer, freelancer, entrepreneur, hobby programmer and student with regard to their incentives for participation on a platform in order to examine motivation factors of complementors. The study indicate that the motives "external rewards" and "status and employment opportunity" were the predominant incentives for complementors on the Facebook platform [14]. Similarly, Hurni et al. [23] distinguish the complementors in their study of the interactions of governance mechanisms of a platform and the 
effect on complementor dedication. In the course of this research objective, the authors define complementor dedication as "the extent to which a complementor is devoted, faithful, and willing to invest in the partnership with a platform owner" [23], showing that there is a strong relationship between complementor dedication and the appropriate rule design of the platform ecosystem.

The fourth differentiation criterion based on the performed literature analysis is the scope of contribution of complementors and their complementary services to platform ecosystems [5, 19, 33-35]. For example, Parker et al. [19] differentiate three types of complementors, named core developers, extension developers and data aggregators with regard to their contribution to the platform ecosystem. According to Parker et al. [19], core developers are individuals employed by the platform owner to develop tools and applications that ensure effective use of the platform by users. Extension developers, on the other hand, are external parties or third-party developers who enhance the functionality of the platform through innovative complementary products, thereby increasing the value of the platform ecosystem. Data aggregators collect various interaction-based data according to platform governance and sell them to specific organizations, enabling them to target e.g. matching advertising to users.

The fifth and last differentiation criterion is the differentiation between complementors in platform ecosystems regarding their organizational form. The majority of scientific studies consider complementors as institutional organizations in the form of (entrepreneurial) business ventures [28, 29, 33]. Some articles consider complementors more as individual entrepreneurs engaged in platform ecosystems [4, 36]. A distinction between the two forms of consideration of the organizational structure and the respective available resources of the complementor is of crucial scientific importance since the strategic capabilities of complementors differ thereby significantly. For example, Miric et al. [29] investigates complementors' actions of capturing and protecting intellectual property in platform ecosystem. Based on the available resources of the complementor and its organizational structure, Miric et al. [29] conclude that many individual, small complementors protect their intellectual property through informal protecting mechanisms, whereas larger business ventures are able to protect their intellectual property through a combination of informal- and formal intellectual property rights mechanisms [29].

In the course of the analysis and interpretation of the analyzed literature, five core dimensions of differentiation between complementors in platform ecosystems emerged as shown in Table 4: the organizational size of the complementor (1), the level of remuneration (2), the motivational factors of participation on platforms (3), the level of contribution of complementors in platform ecosystems (4) and the underlying organizational form of the complementor (5). Thereby, scholars synthesize their differentiation based on the organizational characteristics of complementors $(1,2,5)$ as well as their relation and reciprocal action with the platform ecosystem $(3,4)$. 


\subsection{Contribution of Complementors in Platform Ecosystem Literature}

We found in addition that the reviewed articles consider the influence of complementors on the platform ecosystem from diverse perspectives as shown in Figure 1. First, scholars find that complementors (a) create customer value through innovative complementary products and services [12, 13, 38]. The fundamental decision on the degree to open up the platform and outsource innovation to external parties depends both on the network effects and on the number of complementors [3, 39]. Companies open up their platform to an increasing extent once a certain threshold of complementors are achieved in the market [8]. As soon as companies decide to open the platform to external parties, the number of complementors on the platform itself becomes crucial for the innovation capabilities of the platform ecosystem $[3,8,40]$. An excessive increase of complementors in an ecosystem often leads to a reduction of innovation incentives, which the scientific literature often refers to as the crowding-out effect [13].

Second, researchers regard the contribution of the complementor in (b) providing knowledge to the platform ecosystem [20,36]. The community of participants in a platform ecosystem generates different types of information, which complementors use to identify and exploit entrepreneurial opportunities $[32,39]$. The generation and use of information stimulates thus further growth of the platform $[12,17]$. Additionally, complementors develop knowledge-based information by recombining skills or technological resources with increasing participation in a platform ecosystem [39]. This information and capabilities expand the existing pool of routines, resulting in continuous performance improvement of products or services in a platform ecosystem [20].

A third perspective is (c) the growth of the platform ecosystem through the complementors' complementary products and the resulting customer satisfaction based on network effects [16, 41, 42]. Complementors significantly contribute to the generation of network externalities through their innovative complementary products, as they increase the value of the ecosystem and respond to the needs of heterogeneous user structures $[16,18]$. However, the decision of complementors to interact on a given platform depends on the presence of the platform's network effects as a vast installed-base of users in turn increases the attractiveness of the platform for complementors to pursue entrepreneurial opportunities [42, 43].

The analyzed literature shows academic consensus that complementors contribute in an essential way to the existence and progress of the entire platform ecosystem. As Figure 1 illustrates, researchers mainly focus on increased innovation capabilities of the platform ecosystem through complementors $[3,7$, $39]$, the provision of external knowledge from complementors [12, 17, 20] and the growth potential of the platform by complementary products of complementors $[16,18,44]$. The contribution of complementors, however, is mainly analyzed from the perspective of the platform owner in order to examine the effects of participation on the platform ecosystem. 


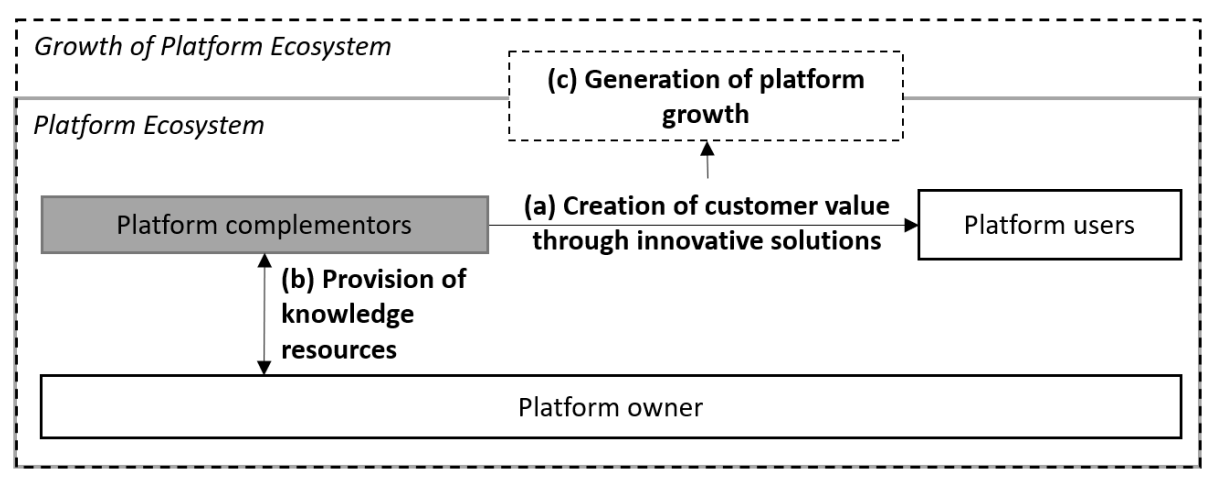

Figure 1. Contribution of Complementors in Platform Ecosystems

\subsection{Relationship between Platform Owner and Complementor}

Based on our literature analysis, we identified four key aspects focusing on the relationship between platform owner and complementor. We also focused in particular on areas of conflict between platform provider and complementor.

Competitive pressure on platforms: Of the 60 articles, 37 articles dealt directly or indirectly with the competition between complementors on platforms. Complementors are primarily independent entrepreneurs and autonomous parties who offer their knowledge and complementary products or services on the platform with significantly different capacities to generate competitive advantages [7, 14, 27]. The scientific literature largely omits that hobby developers, freelancers and developers in small start-ups represent the majority of app developers on mobile platforms [14]. Participating on platforms has significant advantages for complementors, since they have direct access to a large number of consumers without having to build these structures themselves. At the same time, however, the complementors face the challenge of immediately differentiating themselves in a cluster of similar products from other competitors [32]. In order to survive in the market in the long term, the visibility of their complementary products is of decisive importance for the complementors. Due to the strong competitive pressure and the increasing number of complementors on platforms, complementors attempt to place their complementary products on the market through faster development cycles or by entering relevant market niches $[20,27,35]$. This applies in particular to new complements in the market. Experienced and larger complementors succeed more easily in maintaining their superior market position in complex platform ecosystems and in generating sustainable value in the platform ecosystem because of their experience [20].

Besides the direct competition between complementors, three articles dealt with the phenomenon of platform owner entry and its effects on the competitive situation inside the platform ecosystem [28, 37]. In particular, researchers investigated the absorption mechanism, whereby the platform provider offers own complementary products or functionalities that were previously provided by 
complementors [45]. Accordingly, complementors respond comprehensively to the platform owner's entry into its market niche by adapting both value creation and value retention strategies [28]. If there is a threat of market entry by the platform operator, complementors reduce innovation efforts in the affected markets but increase the innovation efforts in the non-affected markets. During this transition, complementors focus more on generating short-term profits through price increases in the affected markets [37]. In addition, the entry of a platform supplier into its own market is perceived differently depending on the individual characteristics of the complementor. While larger, more diverse complementors perceive entry as an opportunity for innovation, smaller complementors increasingly view market entry by the platform provider as threatening to their own market position [28].

Strategy- and Goal Expectancy: When analyzing the relationship between platform owner and complementor, some studies within the literature analysis focus on the strategy- and goal expectancy. In contrast to other market environments, complementors on platforms have to pursue several, sometimes contradictory and externally stipulated business objectives $[4,23,36]$. On the one hand, the platform provider sets goals, visions and structures for the platform ecosystem, which the complementor, as an entrepreneur, has to follow. [36] On the other hand, the complementor must also ensure that his own company differentiates itself sufficiently from the competitors and can survive even if the platform fails [7, 17]. This dual-goal expectancy bears potential conflicts if the goals of the ecosystem operator and the goals of the individual complementor are in strong conflict $[36,41]$. For example, the platform provider may wish to make its platform particularly attractive through pricing campaigns in order to make greater use of network effects, while the complementary complementor pursues the goal of increasing revenues, leading to considerable trade-offs between complementor and platform owner.

Platform Leadership and Power Asymmetries: In the context of platform economics, high power asymmetries can arise in the relationship between complementor and platform operator, as complementors have little or no influence on platform operators' decisions regarding their strategic choices [38]. In particular, tensions in pricing and the provision structure between platform owner and complementor illustrate the asymmetries in the negotiating power between platform provider and complementor $[42,46]$. The imbalances and power asymmetries entail the risk of a loss of trust between platform provider and complementor. However, trust is a significant factor for the relationship between platform provider and complementor for the long-term success of the platform [47]. Platform owners can strengthen trust between complementors in the platform economy, especially through effective governance mechanisms such as intellectual property right protection. A fair and sustainable governance structure has a positive significant impact on the motivation of complementors to engage on the platform [36].

Platform Openness and Governance: The platform openness and governance is an important research topic since the value of a platform relies on its 
complementary products provided by the platform complementor [18, 40, 48]. However, research in this area mainly focused on the role of platform owners' decisions for strategically examining the optimal degree of openness and control of a platform $[49,50]$. The governance and openness of a platform, in addition to income potential, technical skills and individual attitude, is a significant factor in the choice of complementors to engage on a platform [44]. Complementors' engagement is especially high in horizontal platform governance systems in which each complementor receives the same opportunities for value capture and value creation [10]. In addition to the governance structure of the platform and the distribution of decision-making rights, the degree of architectural openness also influences the extent of complementor engagement. Ceteris paribus, the higher the degree of openness of a platform, the lower the barrier for complementors to make asset-specific investments and thus to participate on the platform [4]. The maximum degree of openness of a platform ecosystem suggests that there are no restrictions on participation or use of the platform. Boudreau [3] shows that providing more open access to complementors lead to a significant increase in the development rate of new devices, illustrated by an inverse U-shape relationship between the open structure of a platform and the innovation performance in the platform ecosystem. Complementors show higher innovation incentives for more open platform ecosystem up to the point where the platform is too crowded, which in turn leads to financial constraints for complementors due to price competition, resulting in a loss of attractiveness of the platform $[3,7,44]$.

\section{Discussion}

In this section, we discuss two central issues based on our literature analysis: the heterogeneity of complementors and the individual assessment of complementors in platform ecosystem. We suggest that future research on these issues deepens our understanding of complementors in platform ecosystems, allowing scholars to derive important recommendations for theory and practice.

\subsection{Heterogeneity of Complementors in Platform Ecosystems}

Despite a strong consensus among scholars from IS and management regarding complementors as particularly important in markets with network effects such as platforms $[18,42,43,50]$, the vast majority of studies with direct or indirect focus on the complementor role in the ecosystem consider complementors universally and homogeneously. As illustrated in Table 4, scholars differentiate complementors along different parameters. A scientific consensus how to distinguish and classify complementors is still lacking although complementors differ significantly in numerous dimensions, including size, experience, financial background, strategic orientation or motivation. It is essential for platform owners to understand the heterogeneous complementor structures in their ecosystem in order to be able to adapt their governance rules accordingly and 
ensure long-term success of the platform $[7,40]$. Due to this research gap, existing studies show little insights how platform owners can strategically manage complementors or create incentives for them so far.

A first step could be to analyze the structure of complementors in demographic and economic terms and classify complementors according to these dimensions. For example, Wen et al. (2019) examined strategic reactions of complementors in case of platform-owner entry [37]. According to Wen et al. (2019) the entry of the platform provider leads to a reduction in the innovative capabilities of the complementors and generates a price increase for the applications affected by the entry of the platform owner. A differentiation of complementors in terms of their economic structure could reveal further interesting aspects regarding the response capabilities of complementors, since smaller complementors generally have fewer strategic resources than large complementors. Therefore, considering the heterogeneity of complementors in platform ecosystems might reveal whether and to what extent complementors in a platform ecosystem react differently to the platform provider's entry into their market $[15,44]$.

Distinctions between platform types can also be of central importance, as it can be assumed that the heterogeneous structures of complementors differ according to their openness and the hurdle of entry barriers. IS literature distinguishes mostly between transaction- and innovation platform typologies [51, 52]. A transaction platform is a technology, a product or a service, which facilitates the exchange between different users, buyers or providers as an intermediary (e.g. Uber or eBay), whereas an innovation platform refers to a technology, product or service that serves as a basis on which other organizations are able to develop complementary digital artefacts (e.g. Apple iOS Store, Google Android Platform) [51]. Since different platform typologies have different resource requirements, a differentiation regarding the structure of heterogeneous complementors based on different platform typologies would be of scientific interest. Individual complementors or small entrepreneurial ventures usually have limited resources, so their interactions are more likely to take place on platforms that either use few resources or have extensive resources provided by the platform provider (e.g. app development) [17, 23, 36, 51]. In contrast, institutional organizations with access to diverse resources are able to engage in platform ecosystems that require intensive resource utilization (e.g. videogame development) [23, 29, 51, 52]. For example, for small complementors publishing an application for an open source platform such as Linux is probably easier and cheaper to accomplish than publishing applications in the store of Microsoft Windows, resulting in a likely higher proportion of smaller complementors in Linux. This phenomenon might also affect the boundary objectives of platforms, which are often subject to research in IS literature. Due to limited resources, smaller complementors need to have access to simpler boundary objectives, while large complementors have the resources to handle complex boundary objectives. 


\subsection{Individual Evaluation of Complementors in Platform Ecosystems}

Additionally, the literature research revealed that scientific literature omits the research dimension considering the complementor at the individual level. The perspective of the complementor is based on an abstract representation, seeing complementors as an important part of the ecosystem with regard to the innovation- and growth capabilities of a platform. In line with this argument, research largely omits the individual characteristics, the entrepreneurial needs and the underlying motivation of complementors although e.g. Bergvall-Kåreborn and Howcroft [38] already called for research regarding complementors on an individual level. In particular, small complementors are of great importance, as they represent an economically significant part of the complementor structure from the perspective of the platform provider [29]. The limited awareness of this research strand is surprising, since complementors and their different characteristics are an essential core component in platform ecosystems, having a direct impact on the long-term success of a platform $[3,8,38]$. Through a precise understanding of complementors with regard to their individual characteristics, their entrepreneurial structures and their motivational basis, owners can align their platform governance structure more efficiently and thus achieve significant long-term competitive advantages $[4,36]$.

First scientific articles show interesting approaches to gain a better understanding of complementors on an individual level. Nambisan et al. [36] analyze the self-regulation processes of complementors in platform ecosystems to successfully manage the dual goal expectancy between platform owner and complementor. Hilkert et al. [14] investigate the individual motivation factors of complementors and their influence on the intensity of platform participation. This line of research is, in contrast to research on the impact of complementors on platforms, largely unilluminated. The few scientific articles dealing with the individual consideration of complementors on platforms provide a basis for more scientific investigation $[4,14,23,36]$. On this foundation, a promising approach to this research strand would be to examine the heterogeneous motivational factors of complementors on platforms with regard to their organizational structures and their reciprocal actions with the platform ecosystem.

\subsection{Limitations}

Despite the aforementioned valuable contributions, this literature review is subject to limitations. First, despite greatest care, this literature analysis may not encompass all relevant studies with the mentioned keywords. For instance, authors may have consistently used different synonyms for complementors or platform ecosystems, resulting in a missing coverage of these articles. Second, in order to make the results of this study comparable, we had to simplify and cluster the results of the studies during the coding process. As a result, some articles find no representation in the results as they may have been overlooked or lost during the process. The third and final limitation of this study is that the questions for 
future research based on the presented literature analysis could be influenced by the author's perspective. Hence, there may be additional open research topics for future research. Despite the mentioned and other limitations, this literature analysis offers one of the first explorations regarding the conceptualization of complementors in platform-based ecosystems.

\section{Conclusion}

In this scientific article, we summarized recent literature focusing on the role of complementors in platform ecosystem and derived open topics for future research based on the results of our literature analysis. We showed the different perspectives in current research regarding the conceptualization and the role of complementors in platform ecosystems and aggregated the contributions of the complementors in the platform economy. Furthermore, we identified and highlighted two major issues for future research: First, we suggest that future research must take a closer look at the heterogeneous structures of complementors on platforms. As in other competitive environments, complementors in platform ecosystems differ significantly from each other. So far, this aspect has hardly been taken into account although understanding heterogeneous complementor structures is particularly relevant for platform owners to ensure efficient platform functionality and consistent growth. Second, we recommend to analyze the complementors in the ecosystem of the platform on an individual level. An analysis on an individual level would significantly contribute to our understanding of the complementor and their incentives to interact on a platform. This improved understanding helps platforms to target their governance mechanisms in order to attract certain types of complementors to their platforms.

\section{References}

1. Biggest companies in the world 2019 | Statista, www.statista.com/statistics/263264/top-companies-in-the-world-bymarket-value/

2. Brandenburger, A., Nalebuff, B.: Co-opetition. Doubleday, New York, NY (1998)

3. Boudreau, K.: Open Platform Strategies and Innovation: Granting Access vs. Devolving Control. Management Science 56, 1849-1872 (2010)

4. Nambisan, S., Siegel, D., Kenney, M.: On open innovation, platforms, and entrepreneurship. Strategic Entrepreneurship Journal 12, 354-368 (2018)

5. Wang, R.D., Miller, C.D.: Complementors' engagement in an ecosystem: A study of publishers' e-book offerings on Amazon Kindle. Strat. Mgmt. J 41, 3$26(2020)$ 
6. Schreieck, M., Wiesche, M., Kude, T., Krcmar, H.: Shifting to the Cloud - How SAP's Partners Cope with the Change. In: Proceedings of the 52nd Hawaii International Conference on System Sciences, pp. 6084-6093 (2019)

7. Wareham, J., Fox, P.B., Cano Giner, J.L.: Technology Ecosystem Governance. Organization Science 25, 1195-1215 (2014)

8. Parker, G., van Alstyne, M., Jiang, X.: Platform Ecosystems: How Developers Invert the Firm. MISQ 41, 255-266 (2017)

9. Hein, A., Weking, J., Schreieck, M., Wiesche, M., Böhm, M., Krcmar, H.: Value cocreation practices in business-to-business platform ecosystems. Electronic Markets 29, 503-518 (2019)

10. Jacobides, M.G., Cennamo, C., Gawer, A.: Towards a theory of ecosystems. Strat. Mgmt. J 39, 2255-2276 (2018)

11.Hein, A., Schreieck, M., Wiesche, M., Böhm, M., Krcmar, H.: The emergence of native multi-sided platforms and their influence on incumbents. Electronic Markets 29, 631-647 (2019)

12. Eckhardt, J.T., Ciuchta, M.P., Carpenter, M.: Open innovation, information, and entrepreneurship within platform ecosystems. Strategic Entrepreneurship Journal 12, 369-391 (2018)

13. Boudreau, K.J.: Let a Thousand Flowers Bloom? An Early Look at Large Numbers of Software 'Apps' Developers and Patterns of Innovation. Organization Science 23, 1409-1427 (2012)

14. Hilkert, D., Benlian, A., Hess, T.: Motivational Drivers to Develop Apps for Social Software-Platforms: The Example of Facebook. In: AMCIS 2010 Proceedings. 86.

15. Ghazawneh, A., Henfridsson, O.: A Paradigmatic Analysis of Digital Application Marketplaces. Journal of Information Technology 30, 198-208 (2015)

16. Anderson, E.G., Parker, G.G., Tan, B.: Platform Performance Investment in the Presence of Network Externalities. Information Systems Research 25, 152172 (2014)

17. Srinivasan, A., Venkatraman, N.: Entrepreneurship in digital platforms: A network-centric view. Strategic Entrepreneurship Journal 12, 54-71 (2018)

18. Venkatraman, N.: Preferential Linkage and Network Evolution: A conceptual Model and empirical Test in the U.S.Video Game Sector. Academy of Management Journal 47, 876-892 (2004)

19. Parker, G., van Alstyne, M., Choudary, S.P.: Platform revolution. How networked markets are transforming the economy - and how to make them work for you. W.W. Norton \& Company, New York, London (2017)

20. Kapoor, R., Agarwal, S.: Sustaining Superior Performance in Business Ecosystems: Evidence from Application Software Developers in the iOS and Android Smartphone Ecosystems. Organization Science 28, 531-551 (2017)

21. Davis, J.P.: The Group Dynamics of Interorganizational Relationships. Administrative Science Quarterly 61, 621-661 (2016)

22. Sarker, Sahaym, Bjørn-Andersen: Exploring Value Cocreation in Relationships Between an ERP Vendor and its Partners: A Revelatory Case Study. MIS Quarterly 36, 317-338 (2012) 
23. Hurni, T., Huber, T.L., Dibbern, J., Krancher, O.: Complementor dedication in platform ecosystems: rule adequacy and the moderating role of flexible and benevolent practices. European Journal of Information Systems, 1-24 (2020)

24. Cheng, K., Schreieck, M., Wiesche, M., Krcmar, H.: Emergence of a Post-App Era - An Exploratory Case Study of the WeChat Mini-Program Ecosystem. In: 15th International Conference on Wirtschaftsinformatik (2020)

25. Webster, J., Watson, R.: Analyzing the Past to Prepare for the Future: Writing a Literature Review. MIS Quarterly 26, xiii-xxiii (2002)

26. vom Brocke, J., Simons, A., Niehaves, B., Riemer, K., Cleven, A.: Reconstructing the Giant: On the Importance of Rigour in Documenting the Literature Search Process. In: Seventeenth European Conference on Information Systems, Verona

27. Qiu, Y., Gopal, A., Hann, I.-H.: Logic Pluralism in Mobile Platform Ecosystems: A Study of Indie App Developers on the iOS App Store. Information Systems Research 28, 225-249 (2017)

28. Foerderer, J., Kude, T., Mithas, S., Heinzl, A.: Does Platform Owner's Entry Crowd Out Innovation? Evidence from Google Photos. Information Systems Research 29, 444-460 (2018)

29. Miric, M., Boudreau, K.J., Jeppesen, L.B.: Protecting their digital assets: The use of formal \& informal appropriability strategies by App developers. Research Policy 48 (2019)

30. Benlian, A., Hilkert, D., Hess, T.: How open is this Platform? The Meaning and Measurement of Platform Openness from the Complementers' Perspective. Journal of Information Technology 30, 209-228 (2015)

31. Boudreau, K.J., Jeppesen, L.B.: Unpaid crowd complementors: The platform network effect mirage. Strat. Mgmt. J 36, 1761-1777 (2015)

32. Schaarschmidt, M., Stol, K.-J., Walsh, G., Bertram, M.: Lead Users' Innovative Work Behavior in Digital Platform Ecosystems: A Large Scale Study of App Developers. In: International Conference on Information Systems (ICIS 2019), Munich

33. Huang, P., Ceccagnoli, M., Forman, C., Wu, D.J.: When Do ISVs Join a Platform Ecosystem? Evidence from the Enterprise Software Industry. In: Proceedings of the 30th International Conference on Information Systems, Phoenix, AZ, December 15-18

34. Barlow, M.A., Verhaal, J.C., Angus, R.W.: Optimal distinctiveness, strategic categorization, and product market entry on the Google Play app platform. Strat. Mgmt. J 40, 1219-1242 (2019)

35. Tian, J., Zhao, X., Ling, X.: Technological compatibility between platforms and multi-homing of third-party developers. In: International Conference on Information Systems (ICIS 2019), Munich

36. Nambisan, S., Baron, R.A.: Entrepreneurship in Innovation Ecosystems: Entrepreneurs' Self-Regulatory Processes and Their Implications for New Venture Success. Entrepreneurship Theory and Practice 37, 1071-1097 (2013) 
37.Wen, W., Zhu, F.: Threat of platform-owner entry and complementor responses: Evidence from the mobile app market. Strat. Mgmt. J 40, 13361367 (2019)

38. Bergvall-Kåreborn, B., Howcroft, D.: Persistent problems and practices in information systems development: a study of mobile applications development and distribution. Information Systems Journal 24, 425-444 (2014)

39. Parker, G., van Alstyne, M.: Innovation, Openness, and Platform Control. Management Science 64, 3015-3032 (2018)

40. Ghazawneh, A., Henfridsson, 0.: Balancing platform control and external contribution in third-party development: the boundary resources model. Information Systems Journal 23, 173-192 (2013)

41. McIntyre, D.P., Srinivasan, A.: Networks, platforms, and strategy: Emerging views and next steps. Strat. Mgmt. J 38, 141-160 (2017)

42. Eisenmann, T., Parker, G., van Alstyne, M.: Strategies for two-sided markets. Harvard Business Review 84, 92-101+149 (2006)

43. Katz, M.L., Shapiro, C.: Systems Competition and Network Effects. Journal of Economic Perspectives 8, 93-115 (1994)

44.Um, S., Kang, D., Hahn, J., Yoo, Y.: Popularity and Competition in a Digital Platform Ecosystem: A Network Perspective. In: International Conference On Information Systems (ICIS 2018), San Francisco.

45.Schreieck, M., Wiesche, M., Krcmar, H.: The Platform Owner's Challenge to Capture Value - Insights from a Business-to-Business IT Platform. In: Proceedings of the International Conference on Information Systems (ICIS 2017), Seoul, South Korea, December 10-13, 2017

46. Oh, J., Koh, B., Raghunathan, S.: Value Appropriation between the Platform Provider and App Developers in Mobile Platform Mediated Networks. Journal of Information Technology 30, 245-259 (2015)

47. Perrons, R.K.: The open kimono: How Intel balances trust and power to maintain platform leadership. Research Policy 38, 1300-1312 (2009)

48. Schreieck, M., Wiesche, M., Krcmar, H.: Design and Governance of Platform Ecosystems - Key Concepts and Issues for Future Research. In: TwentyFourth European Conference on Information Systems (ECIS). İstanbul, Turkey (2016)

49. Eisenmann, T.R., Parker, G., van Alstyne, M.: Opening Platforms: How, When and Why? In: Gawer, A. (ed.) Platforms, Markets and Innovation, pp. 131162. Edward Elgar Publishing, Cheltenham, U.K, Northampton, Mass (2009)

50. Parker, G.G., van Alstyne, M.W.: Two-Sided Network Effects: A Theory of Information Product Design. Management Science 51, 1494-1504 (2005)

51. Gawer, A., Evans, P.C.: The Rise of the Platform Enterprise:. A Global Survey. In: The Emerging Platform Economy No. 1 (2016)

52. Reuver, M. de, Sørensen, C., Basole, R.: The digital platform: a research agenda. Journal of Information Technology 33, 124-135 (2018) 